\title{
OIL POLLUTION OF FINNISH GULF BALTIC SEA DUE TO OIL TRANSPORT ACTIVITIES
}

\author{
A.Alhimenko \\ Head of department "Waterways and Harbours» \\ St. Petersburg Technical University \\ Russia
}

\begin{abstract}
The paper describes problems of Oil pollution and Oil spill combating in Finnish Gulf of Baltic Sea due to oil transport activities The main problem for improving situation is to develop new type of criterias estimation of real damage marine ecosystems. This criterias have to become background for financial estimation of damage, technical characteristics needed equipment and oil combating operations.

The mutual influence of cities and ports is obvious enough. Many cities emerged and developed due to geographical location favouring the trade conducted by sea and by river. At the early stages the strong activity of port operations determined the prosperity of the city and the welfare of its residents. But while growing up the port affects more and more negatively the ecological situation in the city.
\end{abstract}

\section{SEA PORTS ACTIVITIES AT REGION OF ST.PETERSBURG}

The current situation in St. Petersburg is now of this kind. It is significantly aggravated by some events of recent history. The former USSR having the choice of Baltic Sea ports could plan the development distributing the load of the cargo traffic more or less evenly but not concentrating it at one port. For this reason the Ventspils port (Latvia), Nowotallinnsky port (Estonia) were constructed, the existing ports were reconstructed. After USSR disintegration and realisation of independence of former Soviet republics there remains St.Petersburg as the only one sea port at the Baltic Sea. 
It is vital for Russia to enlarge significantly the cargo traffic of St.Petersburg's sea port in volume as well as in diversity of cargoes. Such enlargement of goods turnout can influence dramatically upon the ecological conditions in the city of St.Petersburg and Finnish Gulf as whole.

Nowadays the growth rates as well as technologies available depend on the investments. Ecological safety of compound projects and complex technologies are fundamental for the investment process. The inadequate level of ecological safety or the high level of project's ecological risk enhance the investment risk and entail the necessity to change technological concepts in order to enhance the reliability and profitability of credit. In Europe the process of bringing the ecological and economical values into coordination is multi-staged, objective and well developed organizationally. It is to regret that in Russia we do not have the common practice of coordinating economical effectivity indexes with the ecological safety indexes. The problem seems to be especially difficult when considering sea and river ports located in large cities.

For the Russia's North-West and especially for the Leningrad region many large investment projects have been developed. The Department of Sea Transport of Russia has accepted the program for increasing of capacities of Russian ports by factor 1.9 to the year 2000. In 2010 the total annual cargo turnout in Finnish Gulf is planned to amount to 125 mill. tons. Then $50 \%$ of turnout will be such cargoes as raw oil, oil products, liquid gases, liquid chemicals. There are 2 oil ports planned to be constructed on the coasts of the Gulf: the port for the oil products in Batareynaya bay located near to the South-West of the St.Petersburg with the capacity 15 mill. tons per year, and the port in the surroundings of the Primorsk (60 km to the North-West from St.Petersburg) for the oil products, chemicals and liquid gas with the capacity 45 mill. tons per year.

\section{OIL PIPELINES ACTIVITIES}

To transport the oil and oil products from oil fields of Siberia to the ports on the coast of Finnish Gulf the proposals are developed to create the Baltic pipeline system. The project envisages the construction of the new oil pipelines from Haryaga to Usinsk, the new pipelines from Usinsk to Yaroslavl, connection of loopings to the separate pipeline on the section Yaroslavl-Kirishi and the construction of the new pipeline and port complex near Primorsk in Finnish Gulf and continuation of the pipeline to Finland. The competing variants of the pipeline route are from Kirishi to Primorsk continuing to Finland (Porvoo) or to Batareynaya bay continuing on the floor of the Gulf to Primorsk $(60 \mathrm{~km})$. There are also two possibilities for the pipeline Kirishi-Primorsk: the route can go across Gulf of Finland or across Karelia. Also exist various ways to cross the Vyborg bay and Neva river.

The high ecological risk of oil ports and pipelines now in process of design, the possibility of accidents at this objects may have disastrous consequences to local population and environment, define this projects as the most dangerous for the 
region. The preliminary estimations of ecological safety of some projects made by independent scientific organizations contain substantial remarks. These transportation of the oil products via the railway section, located at the distance of $1420 \mathrm{~m}$ from the nearest building of LNPP (Leningrad nuclear power plant) can cause in the case of explosion of the train carrying oil products the creation of the shock wave having in the front the pressure $19.4 \mathrm{kPa}$ and the duration of compression phase up to $235 \mathrm{~ms}$. This values exceed significantly the figures used in the calculations of durability of plant buildings. That is why the accident with railway train can have heavy consequences going very far.

The pipeline projects are based on out-of-date technical solutions, the modern control systems are absent, technical aspects of ecological safety are not provided. We can see the poor quality of project solutions related to safety. For example impossibility to diagnose the small $(2-8$ square $\mathrm{cm})$ cracks, the length of some $\mathrm{km}$ of the sections that can be locked off, the main pipeline integrity check methods being the pipeline pressure check and visual monitoring by inspector staff. That can cause as the consequence high probability of uncontrolled leak to the soil or basin waters up to some thousands tons of oil products. The project plans also the tanks to be constructed for the technological or diesel oil with the capacity of 10000-20000 cubic meters. The linear dimension of injure zone for the people can spread up to $250 \mathrm{~m}$ when the oil products spilt start burning.

The difficult situation can also appear when the oil products leak from the tanker ship in the Batareynaya bay. The distance from port to LNPP is less than from fairway and under unfavourable wind (from North-West) the oil spot can reach the city's aquatory in 6 to 8 hours. If there are waves on the bay surface and the wind is more than $10 \mathrm{~m} / \mathrm{s}$ the oil spot will diffuse into the thickness of water. Then there will be possibility of catching the polluted water by water intake of LNPP. To avoid the consequences it is necessary to deepen the location of water intake of the power plant.

The similar situation can appear when tanker ships of "river-sea" type carrying oil products pass by Neva river. The river goes actually through the centre of the city and falls into Gulf of Finland. The most dangerous case is hitting of the tanker ship into the foundation of one of the numerous bridges. In case of oil products spill the population could be set into danger of water supply system pollution since some of water intakes are located within the border of the city.

Under normal working conditions oil port and oil pipeline do not create the substantial values of environmental unfavourable factors. The main danger is oil product spills on the port aquatory or on the convey canal due to navigation accident with the tanker ship. The accident may be accompanied by oil products ignition, the oil products can leak due to the loss of pipeline integrity to the local basins which will cause theirs contamination, the fire can emerge on the pipelines and oil storages leading to toxic and burnt injures of people on the surrounding territories. The list of consequences of such accidents can be continued. It is a pity that most of pipelines located in the North-West region of Russia are in unsatisfactory condition. Most of them serve more than 30 years. Every year the 
number of accidents at the pipelines accompanied by oil spills to the soil, rivers and lakes is increasing. It is caused by physical aging of the pipelines. To be supposed that the tendency to growing number of accidents will keep in the future. The large scale accidents are quite possible which can influence upon the water quality in coastal regions of northem seas. The accident of late in Usinsk in 1995 can be an example of that. The spilt oil went to the Pechora river and thus to the sea. The different estimations say that the spilt oil quantity amounted to 14000 tons (estimation made by pipeline administration) or 200000 tons (estimation made by "greens" movement). Taking the present situation into account the utmost importance must be attached to the availability of the equipment which will help to avoid the accident and to remove the consequences of the accident if it still happens. It is to regret that such equipment is expensive enough. But comparing the money that must be spent to remove with the consequences of the accident, the cost of the equipment and of compensating measures do not appear too high.

\section{ECOLOGICAL AND ECONOMICAL ESTIMATION OF CONSEQUENCES OIL SPILL}

The calculations of consequences of possible accidents must be accompanied by calculations of possibility of liquidating the consequences of the accidents by forces of local organizations in a short time. It is very important to have the modern systems technologically checking the integrity of the pipeline, ecological monitoring of the conditions of the surrounding territory (sea territory if the pipeline is located in the sea), accident monitoring in order to take urgent decisions automatically in emergency situations. There is no doubt that on the stage of the declarations it is necessary to determine the quantity of the oil products that can be spilt to the environment in the case of leak which depends on the check system effectively. The possibility of transborder transfer of toxic materials in case of ignition of oil products leading to pollution in basins and sea aquatories dictates the necessity of creating the corresponding subsystems of regional automated system of ecological monitoring. When considering and coordinating the project documentation the considerations set forth here must be pointed to as necessary for the continuation of the research and prospector works.

The serious problem which is not solved yet is how to determine criterias for economical and ecological estimation optimal degree cleaning polluted water. For instance, the volume of oil spill on the surface of sea is 1000 cu.m. This oil spill contained by oil booms. Several oil skimmers work under recovering this slick. Recovery rate of oil skimmers $90 \%$. The question is - when oil combating operation may be stopped? According to mathematical analysis, we never could recover all oil. Moreover, recovery rate will decrease with the decreasing the depth of oil film. So, to collect $1000 \mathrm{cu}$.m spilt oil practically impossible. In some time we should to stop operation. The decision about completion operation usually dine by the head of oil combating team. The main criteria for this deci- 
sion is: the effectiveness of oil collection became low due to decreasing the depth of oil film, changing weather conditions or another factors.

Anyway main criteria became effectiveness oil collection, or another words, technical characteristics of equipment. So we can continue oil collection endless, or stop it after oil film become for instance less than $0.1 \mathrm{~mm}$. Even so, we do not know which concentration of oil may be substantial for marine ecosystems in this aquatory. Because of concentration of oil, which may really influence on marine ecosystems depends on many factors such as square of sea surface covered by oil film, time of presence oil film, degree of diffusion in water body etc. No doubt, that oil film impact on marine ecosystems. On the other hand, about $15 \%$ surface Baltic Sea covered by thin oil films during spring time and nobody suggest to clean Baltic Sea by skimmers.

It is obvious necessity to carry out oil combating operations after large accidents with the ships. Also obvious necessity to clean up aquatories of oil terminals after spilling any quantity of oil or oil products. At the same time it is impossible to organize such operation after spilling $100 \mathrm{~kg}$ crude oil in the open sea. There are two reasons for it:

1) the damage of marine ecosystems during trip some ships to the place of oil slick may be more serious than oil slick itself;

2) such operation cost a lot of money, which may be spent on the purposes of prevention oil spills more effectively.

So, the initial problem is to find the threshold point where operation have to start or may be delayed. The final problem is to estimate degree of damage marine ecosystems by oil spill itself and to determine adequate financial compensation of this damage size of insurance payment. These problems are rather complicated and require cooperation different specialists: engineers, biologists, hydraulists etc.

The problem of estimation damage of marine ecosystems by oil spilling is most actual for the conditions of north seas. This work is started now $[1,2]$, but require more participants and financing.

The question of acceptable level of ecological safety is undoubtedly important for the complex industrial objects and sea ports belong to those objects. Nowadays the basic models are developed for the majority of ecologically unfavourable factors, which allow to forecast the unfavourable consequences of the influence of this factors upon health. In 1991 the group of experts in Russia has developed the temporary requirements to the criteria of assessing the regional ecological risk. In the documents of the group it was declared that in the conditions of normal exploitation and accidents during all life period of the potentially dangerous object, including the withdraw from exploitation and disposition of dangerous waste, when estimating the risk level for demographic breakdowns (lethal outcomes) due to any influences caused by those objects, the normatively founded risk values (for a man per year) must be set. The value $1.0 \mathrm{E}(-6)$ per year is proposed as the normal value, with remark that the risk level for the peo- 
ple outside the region including transborder and global effects must be disappearing low: not more than $1.0 \mathrm{E}(-8)$ per year.

The question of acceptable risk level is the key question in the problem of risk control strategy. Obviously, the value can be specifically determined only after the deep analysis of such factors as social and economical development, infrastructure, health care situation, social and psychological perception of the risk by the population etc. It is extremely important to take into account that the people can be exposed simultaneously to different risks from ecologically combined objects. Therefore the criteria of individual summary risk are set and in this way, though very conditionally, the problem of counting the antropogenic risks can be resolved. There also exists the rule that, when estimating the acceptability of the risk of industrial activity, the collective or group risk related to this activity must be obligatorily taken into account. The collective risk is determined usually by interrelation of the number of people which died due to the accident and the probability of the case that this number may be exceeded.

In the current situation in the North-West regions, where the number of potentially dangerous industrial and military objects is so high, all the decisions taken by the regional administrations, the decisions, concerning the vital risk for the people on the specific territory must be based on the objective quantitative risk criteria, the priority must be given to questions of the ecological safety of industrial plants, but not to the goals of production or, more than that, of politics. Obviously, the strategy of risk control, the planning of economical activity, especially of activity related to construction and exploitation of big objects with high grade of potential danger requires to conduct the risk-project in the region to determine the existing antropogene risk, the ways to lessen the risk.

\section{CONCLUSIONS}

1. Necessary to develop way of determination criteria for calculation damage for marine ecosystems from oil spills.

2. The question of the value of acceptable risk level is not quite clear. Research works are necessary. The calculations of the value of acceptable risk level must be conducted using the same methods in both Russia and Europe.

\section{REFERENCES}

Alhimenko A., Bolshev A., Klevanny K., Liukkonen S. (1997). Modelling Oil Pollution Under Ice Cover. In: Proceedings of the 7th International Offshore and Polar Engineering Conference, vol.2, Honolulu, USA, pp.594-601.

Liukkonen S., Rytkonen J., Alhimenko A., Kniazeva E. On the Adhesion of Oil to Ice. In: Proceedings of the 7th International Offshore and Polar Engineering Conference, Honolulu, USA, vol.2, pp.579-586. 